\title{
Antitumor effects of IDN5109 on head and neck squamous cell carcinoma
}

\author{
DAISUKE SANO, HIDEKI MATSUDA, YUKARI ISHIGURO, GOSHI NISHIMURA, \\ MARIKO KAWAKAMI and MAMORU TSUKUDA \\ Department of Biology and Function in the Head and Neck, Yokohama City University \\ Graduate School of Medicine, 3-9 Fukuura, Kanazawa-ku, Yokohama 236-0004, Japan
}

Received August 31, 2005; Accepted October 25, 2005

\begin{abstract}
Taxanes, a new class of antitumor drugs, are effective against a large number of human tumors, although there are problems with drug resistance. The novel taxane, IDN5109, is characterized by its high tolerability, antitumor efficacy, ability to overcome multidrug resistance, and oral bioavailabilty. We investigated the cellular response of IDN5109 to head and neck squamous cell carcinoma (HNSCC), and compared the antitumor activity of IDN5109 with that of paclitaxel. This is the first demonstration of antitumor effects of IDN5109 on HNSCC. In in vitro experiments, IDN5109 showed antiproliferative effects against HNSCC cell lines. After treatment with IDN5109, Bcl-2 and Bcl-XL were down-regulated, Bax was upregulated, and caspase- 3 was activated. After treatment with IDN5109, concentrations of both VEGF and IL-8 in the culture supernatant of HNSCC cells decreased. In in vivo experiments, the oral administration of IDN5109 showed antitumor effects against HNSCC tumor xenografts. Immunohistochemistry showed that IDN5109 inhibited tumor angiogenesis and induced apoptosis in HNSCC cells, producing a decreased blood vessel density and increased apoptosis index. On the basis of these results, IDN5109 is useful as a chemotherapeutic agent against HNSCC.
\end{abstract}

\section{Introduction}

Taxanes are a new class of antitumor drugs that inhibit microtubule disassembly (1). They are potent inhibitors of cell growth and cell cycle progression, inducing apoptotic cell death, and are endowed with antiangiogenic properties. The current clinical taxanes, paclitaxel and docetaxel, are

Correspondence to: Dr Daisuke Sano, Department of Biology and Function in the Head and Neck, Yokohama City University Graduate School of Medicine, 3-9 Fukuura, Kanazawa-ku, Yokohama 236-0004, Japan

E-mail: t046028d@yokohama-cu.ac.jp

Key words: IDN5109, taxane, head and neck squamous cell carcinoma, oral administration, anti-angiogenesis effective against a large number of human tumors with broad activity in solid tumors including ovarian, breast, and nonsmall cell lung carcinoma, as well as head and neck carcinoma $(2,3)$.

Although paclitaxel and docetaxel are the drugs of choice for many chemotherapeutic regimens, some patients are resistant to taxanes. IDN5109, also a taxane, was originally selected for its ability to overcome drug resistance (4). IDN5109 was derived from the diterpene 14-ß-hydroxy-10deaceylbaccatin III extracted from the needles of Taxus wallichiana (5). The therapeutic benefit of IDN5109 was confirmed in preclinical studies. IDN5109 showed an improved pharmacological profile compared with paclitaxel, had antitumor activity after i.v. administration (4), and maintained its antitumor activity after oral administration $(6,7)$.

Taxane-based therapies have shown significant activity in clinical trials in patients with head and neck squamous cell carcinoma (HNSCC) (8-12). Therefore, more effective taxanes may improve the therapeutic options for HNSCC.

The antitumor effect of IDN5109 on HNSCC has not been reported. The purpose of this study was to investigate the cellular response of HNSCC to IDN5109 and evaluate its antitumor efficacy on HNSCC xenografts. We examined cell cycle perturbations, modulation of apoptotic and angiogenic factors, cell growth inhibition, and apoptosis. The efficacy of IDN5109 was compared to that of paclitaxel, the most frequently used taxane in clinical practice (13).

\section{Materials and methods}

Drugs. Paclitaxel was provided by Bristol-Myers/Squibb (Wallingford, CT, USA) and IDN5109 was provided by Bayer (Leverkusen, Germany). The chemical structure of IDN5109 is shown in Fig. 1. For the antiproliferative assay, the two taxanes were dissolved in ethanol at $1 \mathrm{mg} / \mathrm{ml}$, then diluted in culture medium. For the antitumor activity study, paclitaxel was dissolved in absolute ethanol, Cremophor ELP and cold $0.9 \% \mathrm{NaCl}$ solution $(5 \%, 5 \%$ and $90 \%$ of the final volume, respectively), and IDN5109 was dissolved in Tween-80, absolute ethanol, and $0.9 \% \mathrm{NaCl}$ solution $(10 \%$, $10 \%$ and $80 \%$ of the final volume, respectively) according to a previously reported procedure $(4,14)$.

Cell culture. Cell lines derived from human HNSCC were used in this study. The origins of these cell lines were oral 


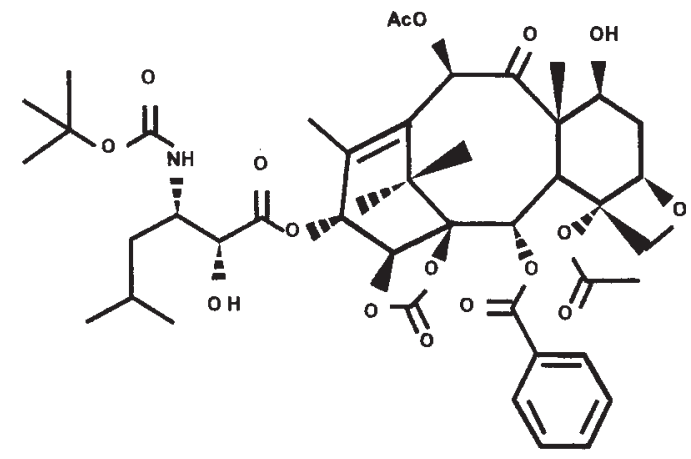

Figure 1. The chemical structure of IDN5109.

floor (YCU OR891), hypopharynx (YCU H891), mesopharynx (YCU M862, KCC M871 and YCU M911), larynx (KCC L871 and YCU L891), tongue (KCC T871 and YCU T873), and maxillary sinus (KCC MS871 and YCU MS861). These cell lines were established in the Department of Otolaryngology, Yokohama City University School of Medicine and the Research Institute, Kanagawa Cancer Center.

All cell lines were maintained in RPMI-1640 medium (Life Technologies Inc., Tokyo, Japan) supplemented with $10 \%$ fetal calf serum, $2 \mathrm{mM}$ glutamin, 100 units $/ \mathrm{ml}$ penicillin, and $100 \mu \mathrm{g} / \mathrm{ml}$ streptomycin at $37^{\circ} \mathrm{C}$ in a $5 \% \mathrm{CO}_{2}$ atmosphere.

In vitro antiproliferative assays. The HNSCC cell lines were grown as suspensions, plated in 96-well plates (Falcon; Becton Dickinson Labware, Lincoln Park, NJ, USA) and treated with drugs $24 \mathrm{~h}$ after seeding at $5 \times 10^{3}$ cells/well. After $48 \mathrm{~h}$ exposure to drugs, the MTT assay was carried out with Tetra Color One (Seigaku Co., Ltd. Tokyo, Japan). Relative growth inhibition was calculated compared to vehicle-treated control cells, and $\mathrm{IC}_{50}$ values were determined as the drug concentrations showing $50 \%$ survival.

Cell cycle analysis. For cell cycle analysis, YCU H891 cells were trypsinized and fixed in $70 \%$ ethanol after $24 \mathrm{~h}$ of treatment with taxanes. Cell cycle perturbations were measured on propidium iodide-stained cells using a FACScan flow cytometer.

Western blot analysis. YCU H891 tumor cells were grown in a 100-mm plastic dish (Falcon), then exposed to IDN5109 $(0.005 \mu \mathrm{g} / \mathrm{ml})$ for $48 \mathrm{~h}$. After removal of media, cells were washed twice with PBS and lysed with lysis buffer $(10 \mathrm{mM}$ Tris- $\mathrm{HCl}, \mathrm{pH} 7.5,1 \mathrm{mM} \mathrm{MgCl} 2,1 \mathrm{mM}$ EGTA, 0.5\% CHAPS, $10 \%$ glycerol, $5 \mathrm{mM}$ mercaptoethanol, and $0.1 \mathrm{mM}$ phenylmethylsulphonyl fluoride). After the removal of cell debris by centrifugation, protein concentration was determined. Equal amounts of proteins were separated by SDS-PAGE, then transferred onto nitrocellulose membranes. Membranes were reacted with (1:1000 diluted) primary antibodies to Bcl-2, Bcl-XL and Bax (Santa Cruz Biotechnology, Santa Cruz, CA, USA). The reaction was developed using the ECL detection kit (Amersham Biosciences, UK) and exposed to photographic film.

Evaluation of caspase-3. YCU H891 tumor cells $\left(1 \times 10^{6}\right)$ were grown in a $100-\mathrm{mm}$ plastic dish (Falcon), then exposed
Table I. Antiproliferative activity of taxanes.

\begin{tabular}{llcc}
\hline & & \multicolumn{2}{c}{$\mathrm{IC}_{50}(\mu \mathrm{g} / \mathrm{ml})$} \\
\cline { 3 - 4 } HNSCC cell line & Primary sites & IDN5109 & Paclitaxel \\
\hline YCU H891 & Hypopharynx & 0.012 & 0.02 \\
KCC L871 & Larynx & 0.050 & 0.70 \\
KCC T871 & Tongue & 0.350 & 3.90 \\
KCC MS871 & Maxillary sinus & 0.050 & 0.10 \\
YCU M862 & Mesopharynx & 0.070 & 0.40 \\
KCC M871 & Mesopharynx & 0.030 & 2.40 \\
YCU MS861 & Maxillary sinus & 0.038 & 0.78 \\
YCU L891 & Larynx & 0.090 & 7.60 \\
YCU M911 & Mesopharynx & 0.070 & 0.74 \\
YCU OR891 & Floor of the mouth & 0.018 & 0.45 \\
YCU T873 & Tongue & 0.060 & 3.90 \\
\hline
\end{tabular}

In the proliferation assay described in Materials and methods, tumor cells were exposed to taxanes for $48 \mathrm{~h}$. Data are expressed as $\mathrm{IC}_{50}$, the drug concentration (in $\mu \mathrm{g} / \mathrm{ml}$ ) that causes $50 \%$ inhibition of cell proliferation.

Table II. Cell cycle distribution in YCU H891 cells with IDN5109 and paclitaxel.

\begin{tabular}{lccc}
\hline Treatment & $\mathrm{G}_{0}-\mathrm{G}_{1}(\%)$ & $\mathrm{S}(\%)$ & $\mathrm{G}_{2}-\mathrm{M}(\%)$ \\
\hline Control & 53.7 & 27.7 & 18.6 \\
Paclitaxel & 20.0 & 27.1 & 53.0 \\
IDN5109 & 3.8 & 42.9 & 53.2 \\
\hline
\end{tabular}

Cell cycle distribution in YCU H891 cells treated with IDN5109 $(0.01 \mu \mathrm{g} / \mathrm{ml})$ and paclitaxel $(0.02 \mu \mathrm{g} / \mathrm{ml})$. After $24 \mathrm{~h}$ treatment, cells were harvested, fixed, stained with propidium iodide, and analyzed by flow cytometry.

to IDN5109 $(0.001,0.01$, and $0.1 \mu \mathrm{g} / \mathrm{ml})$ for $48 \mathrm{~h}$. After the removal of media, cells were lysed with lysis buffer. After the removal of cell debris by centrifugation, the protein concentration was determined, and caspase-3 activity was measured with an Apopcyto Colorimetric Assay kit (MBL, Nagoya, Japan).

Evaluation of VEGF and IL-8 secretion. YCU H891 cells $\left(1 \times 10^{6}\right)$ were seeded in a $100-\mathrm{mm}$ plastic dish (Falcon). The supernatant of the cells was treated with $0.005 \mu \mathrm{g} / \mathrm{ml}$ of IDN5109. After $48 \mathrm{~h}$, concentrations of vascular endothelial growth factor (VEGF) and interleukin-8 (IL-8) were determined using the Quantine ELISA kit (R\&D System, Minneapolis, MN, USA). The protein concentration of these factors was measured by absorbance compared with a standard curve and analyzed by $\mathrm{NJ}-2100$.

In vivo antitumor activity studies. All in vivo experiments were carried out using 6-week-old female athymic nude (nu/nu) mice weighing 20-25 g (Oriental Yeast Co., Ltd., Tokyo, Japan). Mice were maintained in laminar flow rooms with constant temperature and humidity. The animals were 
YCU H891

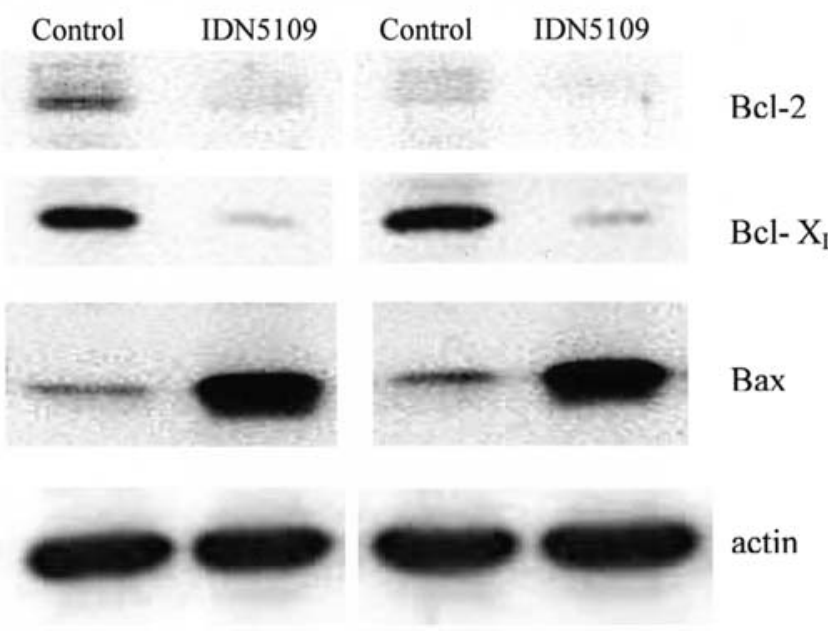

Figure 2. Effect of taxanes on Bcl-2, Bcl- XL, and Bax expression in YCU H891 and KCC MS871 cells. Cells were treated for $48 \mathrm{~h}$. Whole-cell extracts were processed for immunoblotting with anti-Bcl-2, anti-Bcl-XL, or anti-Bax antibodies. After treatment with IDN5109, Bcl-2 and Bcl-XL were downregulated and Bax was upregulated.

maintained and the experiments conducted at the Yokohoma City University School of Medicine Laboratory Animal Facility according to the guidelines for animal experiments set by the Animal Experiment Committee of Yokohama City Univesity School of Medicine.

YCU H891 cells from in vitro cell culture were inoculated subcutaneously into the right flank of athymic mice $\left(1 \times 10^{7}\right.$ cells/mice). Each control or drug-treated group included five mice bearing lateral subcutaneous tumors. Tumors were implanted on day 0 , and tumor growth was followed by weekly measurements of tumor diameters with a Vernier caliper. Tumor weight (TW) was calculated according to the formula: TW $(\mathrm{mg})=$ tumor volume $\left(\mathrm{mm}^{3}\right)=d^{2} \times D / 2$, where $d$ and $D$ are the shortest and longest diameter, respectively. Drug treatment was started when mean TW was 50-100 mm m $^{3}$ IDN5109 and paclitaxel were administered p.o. or i.v. every 4th day, 3 times at a dose of $54 \mathrm{mg} / \mathrm{kg}$. Control mice were given the solvent solution.

Evaluation of vessel density. To evaluate vessel density, an immunohistochemical technique was used. The vessels in the tumor tissues were stained using an antibody to CD31, an endothelial marker (1:200; BD Biosciences, Tokyo, Japan). YCU H891 tumors were harvested and immediately frozen in OCT medium for cryosection. Tumor sections at $6 \mu \mathrm{m}$ were prepared and fixed in cold acetone. The sections were blocked with $2 \%$ goat serum and $1 \%$ bovine serum albumin in PBS, then stained with the antibody. Slides were developed using 3,3'-diaminobenzidine substrate biotinylated peroxidase reagent (Vector Laboratories, Inc., Burlingame, CA). The number of vessels and subsets were scored from a minimum of five microscopic fields from five independent tumors treated with IDN5109 or control groups. The average number of vessels per field was determined under a microscope at a x20 magnification.
Evaluation of apoptosis. Terminal deoxynucleotidyl transferasemediated cUDP nick-end labeling (TUNEL) was done for evaluation of apoptosis. This was done with an Apoptosis In Situ Detection kit (Wako Chemical, Osaka, Japan) for frozen sections. The number of immunoreactive cells based on the distribution of apoptotic cells was scored from a minimum of five microscopic fields of each section treated with IDN5109 or the control groups. The apoptotic index was shown as a percentage of TUNEL-positive cells relative to the total number of cells. For statistical comparison, TW of treated versus control mice was compared using the Student's t-test (two-tailed), and $\mathrm{p}<0.05$ was considered significant.

\section{Results}

Antiproliferative effect of IDN5109 on HNSCC cells. We first determined the antiproliferative effect of IDN5109 on HNSCC cells. Cells were cultured with media alone (control) or media containing IDN5109 $(0-1.0 \mu \mathrm{g} / \mathrm{ml})$. As shown in Table I, HNSCC cells were more sensitive to IDN5109 than paclitaxel. The $\mathrm{IC}_{50}$ of IDN5109 ranged between 0.012 and $0.090 \mu \mathrm{g} / \mathrm{ml}$. On the other hand, the $\mathrm{IC}_{50}$ of paclitaxel ranged between 0.02 and $3.90 \mu \mathrm{g} / \mathrm{ml}$.

Cell cycle distribution. We next examined the mechanism by which IDN5109 caused cell death in HNSCC cell lines. Cell cycle analysis with flow cytometry indicated that exposure to IDN5109 for $24 \mathrm{~h}$ induced a significant arrest in the $\mathrm{G}_{2} / \mathrm{M}$ phase of the cell cycle, similar to exposure to paclitaxel (Table II). The antitumor effects of paclitaxel are generally believed to result mainly from interference with the normal function of microtubules and blockage of cell cycle progression in the $\mathrm{G}_{2} / \mathrm{M}$ phase $(15,16)$. This indicates that IDN5109 has a cell death mechanism similar to that of paclitaxel.

Induction of apoptosis regulators by IDN5109. To further explore mechanisms of molecular cell death induced by IDN5109, we examined the expression of apoptosis regulators Bcl-2 (anti-apoptotic protein), Bcl-XL (anti-apoptotic protein), and Bax (pro-apoptotic protein) after treatment with IDN5109. YCU H891 and KCC MS871 cells were treated with control medium or IDN5109 $(0.005 \mu \mathrm{g} / \mathrm{ml})$ for $48 \mathrm{~h}$, and Western blot analysis was performed. The effects of IDN5109 treatment are illustrated in Fig. 2. After treatment with IDN5109, Bcl-2 and Bcl-XL were down-regulated and Bax was up-regulated. This shows that IDN5109 has the ability to induce apoptosis.

Activation of caspase-3 by IDN5109. To demonstrate the activity of caspase- 3 in apoptosis caused by taxanes, YCU H891 cells were incubated in media alone (control) or media containing IDN5109 $(0.001-1.0 \mu \mathrm{g} / \mathrm{ml})$ or paclitaxel $(0.001$ $1.000 \mu \mathrm{g} / \mathrm{ml})$. Caspase-3 activity was examined using a Colorimetric Assay kit. As shown in Fig. 3, caspase-3 activation was observed in YCU H891 cells treated with IDN5109 with a significant difference between the group treated with IDN5109 and the control. The activation induced by IDN5109 was significantly superior to that by paclitaxel. This indicates that IDN5109 has a higher ability to induce apoptosis than paclitaxel. 

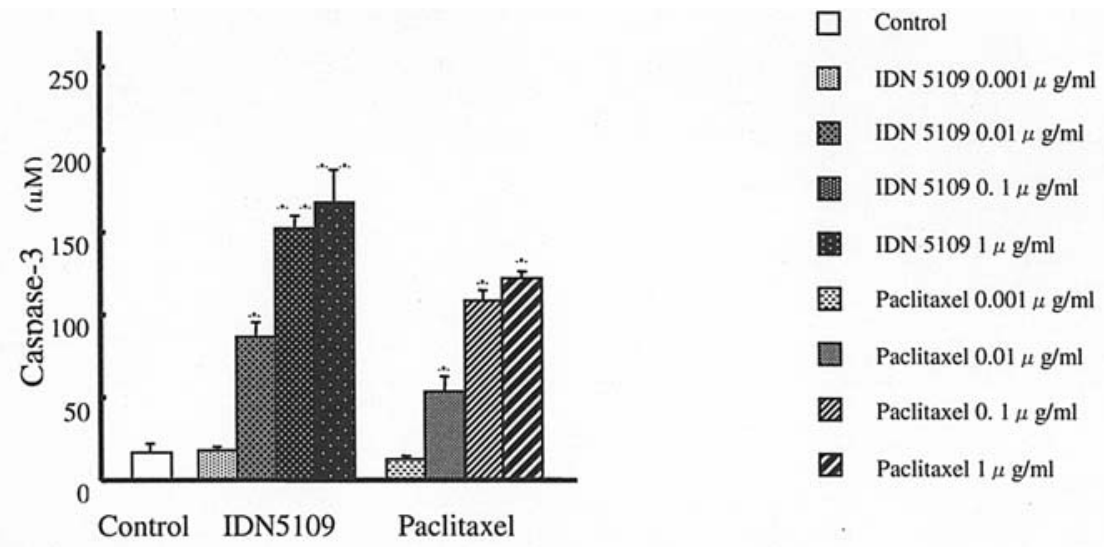

Figure 3. Caspase-3 activity measured with an Apopcyto Colorimetric Assay kit was significantly increased with treatment of IDN5109. "p<0.05 versus control. ${ }^{* *} \mathrm{p}<0.01$ versus control.

VEGF

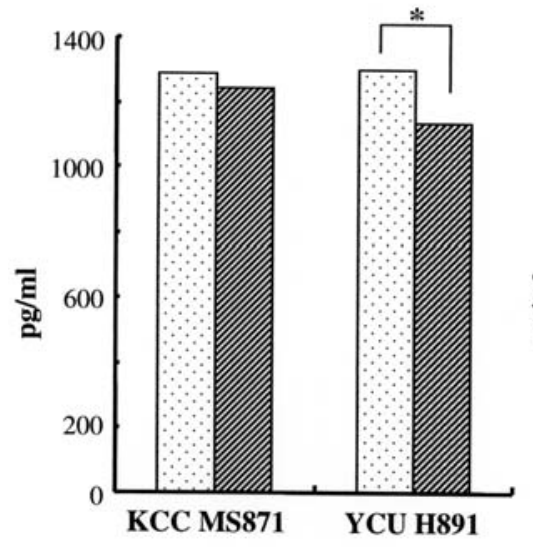

IL-8

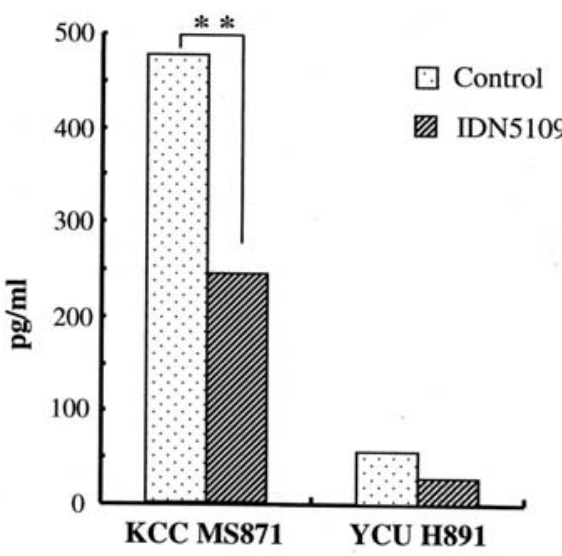

Figure 4. The concentrations of angiogenic factors in supernatant of HNSCC cells, as detected with ELISA. VEGF concentration was significantly decreased in YCU H891, and the IL-8 concentration was significantly decreased in KCC MS871. ${ }^{*} \mathrm{p}<0.05$ versus control. ${ }^{* *} \mathrm{p}<0.01$ versus control.

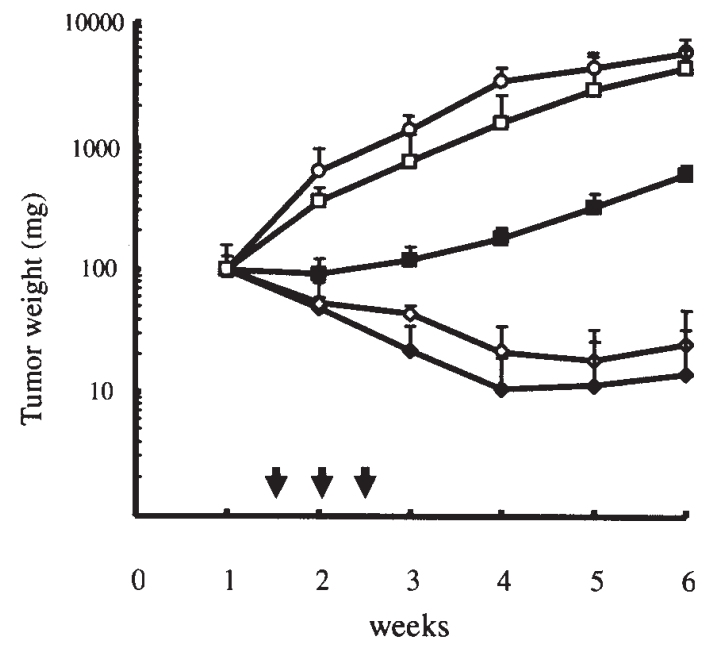

Figure 5. Growth curve of HNSCC YCU H891, xenografted in nude mice after taxane treatment (every 4th day, 3 times). Control (o); $54 \mathrm{mg} / \mathrm{kg}$ p.o. paclitaxel (๖); $54 \mathrm{mg} / \mathrm{kg}$ p.o. IDN5109 (๘); $54 \mathrm{mg} / \mathrm{kg}$ i.v. paclitaxel (*); and $54 \mathrm{mg} / \mathrm{kg}$ i.v. IDN5109 (•). Arrows, days of treatment

Suppression of VEGF and IL-8 by IDN5109. The suppression of VEGF and IL-8 was examined by ELISA using YCU H891 and KCC MS871 cells. As shown in Fig. 4, both factors decreased after exposure to IDN5109 $(0.005 \mu \mathrm{g} / \mathrm{ml}$, $48 \mathrm{~h}$ ). This shows that IDN5109 has the ability to reduce the suppression of these two angiogenic factors.

In vivo studies of the antitumor effects of taxanes on $Y C U$ H891. Fig. 5 shows the the antitumor effects of IDN5109 and paclitaxel against YCU H891 xenografts. We compared the effects of the two taxanes at the maximum tolerated dose of paclitaxel (4). We also compared the efficacy of i.v. and oral administration of IDN5109, and the efficacy of oral administration of IDN5109 and paclitaxel. The best antitumor efficacy was achieved by IDN5109 given i.v. Oral administration of IDN5109 was less effective than i.v., but there was still a significant difference between the group given IDN5109 p.o. and the control group. Paclitaxel given p.o. did not show any activity.

Inhibition of angiogenesis and induction of apoptosis by IDN5109. To investigate the effect of IDN5109 on tumor neovascularization, an effect that has been reported to contribute to the in vivo efficacy of taxanes $(17,18)$, we analyzed the vessel density of the tumors using antibodies against CD31. Fig. 6 shows that treatment with IDN5109 had significant antiangiogenic activity compared with the control. 
A
TUNEL
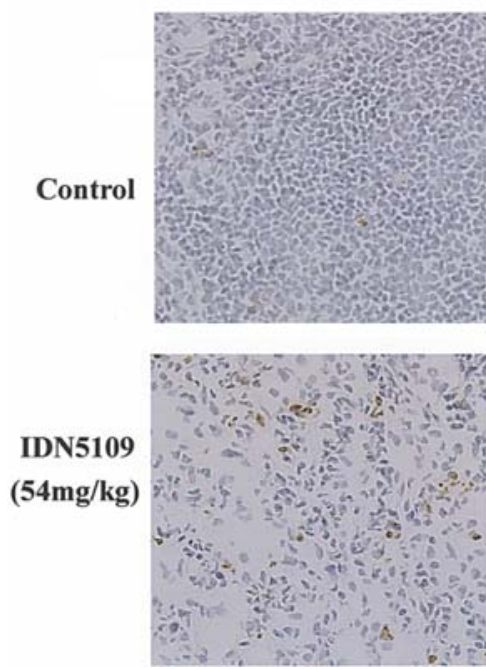

B

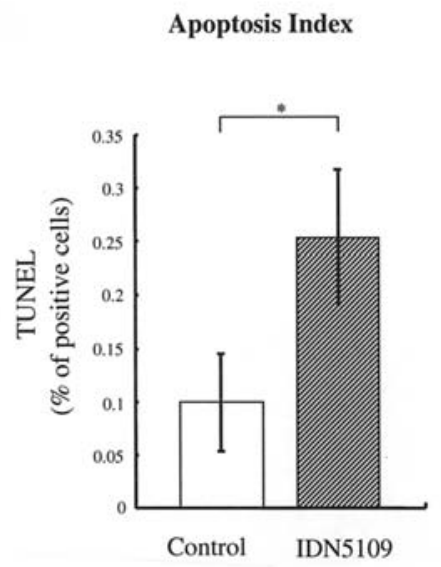

CD31
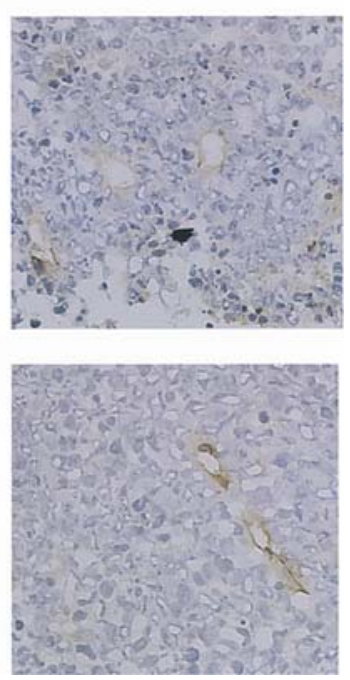

CD31 Staining

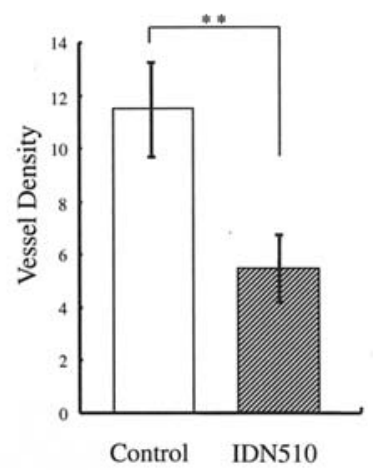

Figure 6. Tissue-based studies of YCU H891 tumor xenografts treated with IDN5109 (54 mg/kg/d). (A) Immunohistochemical analysis of tumor cells stained with an antibody to CD31 and apoptosis by TUNEL (original magnification, x200). (B) Apoptosis index (TUNEL) and CD31 vessel staining. Results are expressed as a percentage of positive cells for each marker (Student's t-test; ${ }^{*} \mathrm{p}<0.05$ and ${ }^{* *} \mathrm{p}<0.01$ ).

We then examined apoptotic cell death induced by IDN5109 in vivo. The treatment with IDN5109 resulted in an increase of TUNEL-positive cells. Quantitative data are summarized in Fig. 6B. The apoptotic index was significantly higher in the group treated with $54 \mathrm{mg} / \mathrm{kg}$ of IDN5109 than the control group.

\section{Discussion}

This is the first detailed study of the effects of IDN5109 on HNSCC in vitro and in vivo. In this study, IDN5109 proved to be an effective drug for suppressing the growth of HNSCC cells both in vitro and in vivo. IDN5109 displayed a higher efficacy than paclitaxel in vitro and comparable antitumor activity on nude mice bearing an established xenograft of YCU H891 cells.

Furthermore, IDN5109 given p.o. was active against HNSCC xenografts, whereas paclitaxel given p.o. showed a complete lack of antitumor efficacy. The hypothesis that IDN5109 given p.o. had a high bioavailability is based on the fact that IDN5109 is a poorly sensitive substrate to P-gp (7), whereas paclitaxel is a highly sensitive substrate as documented in many studies $(1,19)$. P-gp plays a role in drug excretion from the circulation into the intestinal lumen after i.v. treatment and limits oral absorption of the drug $(20,21)$. It has been reported that IDN5109 is the first taxane with good oral bioavailability (7). Although the effects of IDN5109 achieved by oral delivery were lower than those achieved by i.v. treatment at the same dose level, IDN5109 given p.o. was able to suppress the growth of HNSCC cells.

We also examined the mechanism by which IDN5109 caused apoptosis in HNSCC cells. In apoptosis, as a result of triggering apoptotic signals, a cascade of specific cysteine proteases, the caspases (ICE/CED-3 protease family) are activated $(22,23)$. In this study, in YCU H891, IDN5109 induced increased caspase-3 activation, which was involved in IDN5109-induced apoptosis of HNSCC cells.

We also demonstrated that apoptosis regulatory proteins, i.e. Bcl-2, Bcl-XL and Bax, were regulated in IDN5109 to induce apoptotic events in HNSCC cells. Bcl-2 and Bcl-XL proteins serve as suppressors of cell death. On the other hand, Bax proteins are considered inducers of cell death (24). IDN5109 increased Bax expression, while Bcl-2 and Bcl-XL were decreased by IDN5109.

To evaluate apoptotic events in vivo, the TUNEL method was used. After treatment with IDN5109, there was an increased number of TUNEL-positive tumor cells and the apoptotic index was significantly higher in tumors treated with IDN5109 than in the control. These results indicated that IDN5109 induced apoptotic events in HNSCC cells and had an antiproliferative effect on HNSCC cells.

Cell cycle analysis with flow cytometry indicated that exposure to IDN5109 induced a significant arrest in the $\mathrm{G}_{2} / \mathrm{M}$ phase of the cell cycle, similar to exposure to paclitaxel. Because cells at the $G_{2} / M$ phase are considered to be highly sensitive to radiation (25-27), many investigators believe that the combination of paclitaxel and radiotherapy may produce an additive or synergistic effect due to the ability of paclitaxel to induce cell cycle arrest at the $\mathrm{G}_{2} / \mathrm{M}$ phase. On the basis of the cell cycle analysis, IDN5109 also appears to induce high sensitivity to radiation, similar to paclitaxel.

Tumor angiogenesis is the process leading to the formation of blood vessels within a tumor and plays a key role in cancer cell survival, local tumor growth, and the development of distant metastasis (28). Some chemotherapeutic drugs have been reported to have antiangiogenic activity $(29,30)$. A variety of growth promoting factors, e.g. VEGF, IL-8, and other proteins and peptides, can induce angiogenesis (31). The overexpression of these factors has been positively correlated with lymph node metastasis and prognosis in HNSCC $(32,33)$. It has been suggested that the downregulation of VEGF can contribute to the angiogenic properties of paclitaxel (34), although the mechanisms underlying such an effect are unknown. In this study, we found that IDN5109 effectively reduced VEGF and IL-8 production in HNSCC cells in vitro. The suppressive effect of IDN5109 on VEGF production, as observed in in vitro-treated YCU H891 cells, may affect tumor growth in vivo both by 
acting directly on tumor cells and indirectly suppressing tumor neovascularization as in Fig. 6.

In conclusion, we showed that IDN5109 was a highly active agent for HNSCC cells by inducing apoptosis and inhibiting angiogenesis. Even after p.o. administration, it appears to have good efficacy and is a useful chemotherapeutic agent against HNSCC cells.

\section{References}

1. Horwitz SB, Cohen D, Rao S, Ringel I, Shen HJ and Yang CP: Taxol: mechanisms of action and resistance. J Natl Cancer Inst Monogr 15: 55-61, 1993.

2. Rowinsky EK and Donehower RC: Paclitaxel (taxol). N Engl J Med 332: 1004-1014, 1995.

3. Crown J and O'Leary M: The taxanes: an update. Lancet 355: 1176-1178, 2000.

4. Polizzi D, Pratesi G, Tortoreto M, et al: A novel taxane with improved tolerability and therapeutic activity in a panel of human tumor xenografts. Cancer Res 59: 1036-1040, 1999.

5. Appendino G, Gariboldi P, Gabetta B, Pace R, Bombardelli E and Veterbo D: 14-ß-hydroxy-10-deaceyl-baccatin, a new taxane from Himalayan yew (Taxus wallichiana zucc.). J Chem Soc Perkin Trans 1: 2925-2929, 1992.

6. Polizzi D, Pratesi G, Monestiroli S, et al: Oral efficacy and bioavailability of a novel taxane. Clin Cancer Res 6: 2070-2074, 2000.

7. Nicoletti MI, Colombo T, Rossi C, et al: IDN5109, a taxane with oral bioavailability and potent antitumor activity. Cancer Res 60: 842-846, 2000.

8. Colevas AD, Norris CM, Tishler RB, et al: Phase II trial of docetaxel, cisplatin, fluorouracil, and leucovorin as induction for squamous cell carcinoma of the head and neck. J Clin Oncol 17: 3503-3511, 1999.

9. Schoffski P, Catimel G, Planting AS, et al: Docetaxel and cisplatin: an active regimen in patients with locally advanced, recurrent or metastatic squamous cell carcinoma of the head and neck. Results of a phase II study of the EORTC Early Clinical Studies Group. Ann Oncol 10: 119-122, 1999.

10. Koukourakis MI, Bizakis JG, Skoulakis CE, et al: Combined irinotecan, docetaxel and conventionally fractionated radiotherapy in locally advanced head and neck cancer. A phase I dose escalation study. Anticancer Res 19: 2305-2309, 1999.

11. Tsukuda M, Mikami Y, Tanigaki Y, et al: Phase I trial of combined chemotherapy with docetaxel, cisplatin, and 5fluorouracil for patients with locally advanced squamous cell carcinoma of the head and neck. Int J Clin Oncol 9: 161-166, 2004.

12. Katori H, Tsukuda M, Mochimatu I, et al: Phase I trial of concurrent chemoradiotherapy with docetaxel, cisplatin and 5fluorouracil (TPF) in patients with locally advanced squamous cell carcinoma of the head and neck (SCCHN). Br J Cancer 90: 348-352, 2004.

13. Goldspiel BR: Clinical overview of the taxanes. Pharmacotherapy 17: 110S-125S, 1997.

14. Cassinelli G, Lanzi C, Supino R, et al: Cellular bases of the antitumor activity of the novel taxane IDN5109 (BAY59-8862) on hormone-refractory prostate cancer. Clin Cancer Res 8: 2647-2654, 2002.
15. Schiff PB, Fant J and Horwitz SB: Promotion of microtubule assembly in vitro by taxol. Nature 277: 665-667, 1979.

16. Schiff PB and Horwitz SB: Taxol stabilizes microtubules in mouse fibroblast cells. Proc Natl Acad Sci USA 77: 1561-1565, 1980.

17. Belotti D, Vergani V, Drudis T, et al: The microtubule-affecting drug paclitaxel has antiangiogenic activity. Clin Cancer Res 2: 1843-1849, 1996.

18. Sweeney CJ, Miller KD, Sissons SE, et al: The antiangiogenic property of docetaxel is synergistic with a recombinant humanized monoclonal antibody against vascular endothelial growth factor or 2-methoxyestradiol but antagonized by endothelial growth factors. Cancer Res 61: 3369-3372, 2001.

19. Rowinsky EK, Cazenave LA and Donehower RC: Taxol: a novel investigational antimicrotubule agent. J Natl Cancer Inst 82: $1247-1259,1990$.

20. Sparreboom A, van Asperen J, Mayer U, et al: Limited oral bioavailability and active epithelial excretion of paclitaxel (Taxol) caused by P-glycoprotein in the intestine. Proc Natl Acad Sci USA 94: 2031-2035, 1997.

21. Fujita H, Okamoto M, Takao A, Mase H and Kojima H: Pharmacokinetics of paclitaxel in experimental animals. Part 1. Blood level. Jpn J Cancer Chemother 21: 653-658, 1994.

22. Alnemri ES, Livingston DJ, Nicholson DW, et al: Human ICE/CED-3 protease nomenclature. Cell 87: 171, 1996.

23. Budihardjo I, Oliver H, Lutter M, Luo X and Wang X: Biochemical pathways of caspase activation during apoptosis. Annu Rev Cell Dev Biol 15: 269-290, 1999.

24. Green DR, Reed JC: Mitochondria and apoptosis. Science 281: 1309-1312, 1998.

25. Terasima T and Tolmach LJ: Variations in several responses of HeLa cells to $\mathrm{X}$-irradiation during the division cycle. Biophys $\mathrm{J}$ 3: 11-33, 1963.

26. Sinclair WK and Morton RA: X-ray sensitivity during the cell generation cycle of cultured Chinese hamster cells. Radiat Res 29: 450-474, 1966.

27. Withers HR, Mason K, Reid BO, et al: Response of mouse intestine to neutrons and gamma rays in relation to dose fractionation and division cycle. Cancer 34: 39-47, 1974.

28. Kerbel RS: Tumor angiogenesis: past, present and the near future. Carcinogenesis 21: 505-515, 2000.

29. Miller KD, Sweeney CJ and Sledge GW Jr: Redefining the target: chemotherapeutics as antiangiogenics. J Clin Oncol 19: 1195-1206, 2001

30. Schirner M: Antiangiogenic chemotherapeutic agents. Cancer Metastasis Rev 19: 67-73, 2000.

31. Folkman J and Klagsbrun M: Angiogenic factors. Science 235: 442-447, 1987.

32. Tanigaki Y, Nagashima Y, Kitamura Y, Matsuda H, Mikami Y and Tsukuda M: The expression of vascular endothelial growth factor-A and -C, and receptors 1 and 3: correlation with lymph node metastasis and prognosis in tongue squamous cell carcinoma. Int J Mol Med 14: 389-395, 2004.

33. Chen Z, Malhotra PS, Thomas GR, et al: Expression of proinflammatory and proangiogenic cytokines in patients with head and neck cancer. Clin Cancer Res 5: 1369-1379, 1999.

34. Lau DH, Xue L, Young LJ, Burke PA and Cheung AT: Paclitaxel (Taxol): an inhibitor of angiogenesis in a highly vascularized transgenic breast cancer. Cancer Biother Radiopharm 14: 31-36, 1999. 